\title{
The objective evaluation of obstructive pulmonary diseases with spirometry
}

\author{
This article was published in the following Dove Press journal: \\ International Journal of COPD \\ 25 August 2016 \\ Number of times this article has been viewed
}

\author{
Sevket Ozkaya' \\ Adem Dirican ${ }^{2}$ \\ Tibel Tuna ${ }^{3}$ \\ 'Department of Pulmonary Medicine, \\ Faculty of Medicine, Bahçeşehir \\ University, Istanbul, ${ }^{2}$ Department \\ of Pulmonary Medicine, Samsun \\ Medical Park Hospital, ${ }^{3}$ Department \\ of Pulmonary Medicine, Samsun \\ Chest Diseases and Thoracic Surgery \\ Hospital, Samsun, Turkey
}

\begin{abstract}
Airway obstruction is variable in asthma, while it is progressive and persistent in chronic bronchitis and emphysema. However, some of the patients presenting with symptoms of chronic airway diseases have clinical features of both asthma and COPD. The group with "Asthma-COPD Overlap Syndrome" (ACOS) phenotype was characterized by definitely irreversible airway obstruction accompanied by symptoms and signs of reversibility. In this study, we aimed to classify obstructive airway diseases by clinical, radiological, and pulmonary function tests. Patients at Samsun Medical Park Hospital Chest Diseases outpatient clinic were evaluated between January 2013 and April 2016, and a total of 235 patients were included in this study. Mean age of the patients was $55.3 \pm 14.5$ (15-88) years, and the male/female ratio was $45 / 190$. The baseline pulmonary function test results of the patients were as follows: mean forced vital capacity (FVC) values 2,825 $\pm 1,108$ $(710-6,870) \mathrm{mL}$ and $74.3 \pm 22.4(24-155) \%$, forced expiratory volume in 1 second $\left(\mathrm{FEV}_{1}\right)$ values $1,789 \pm 774(480-4,810) \mathrm{mL}$ and $58.1 \pm 20.0(20-130) \%, \mathrm{FEV}_{1} / \mathrm{FVC}$ values $62.5 \pm 6.8(39-70) \%$. Reversibility criteria following bronchodilator treatment were present in 107 (45.5\%) patients. We specified five subgroups for patients according to their clinical, radiological, and pulmonary test findings, namely Group 1 (asthma), Group 2 (ACOS), Group 3 (chronic bronchitis), and Group 4 (emphysema). Additionally, a group of patients who had clinical and spirometric features of both asthma and chronic bronchitis in association with underlying emphysema (emphysema with chronic bronchitis and emphysema with asthma) was defined as the undifferentiated obstruction (UNDO) group. Number and percentage distribution of patients by groups were $58(24.7 \%)$ in the asthma group, 70 (29.8\%) in the ACOS group, 61 (26\%) in the chronic bronchitis group, 32 (13.6\%) in the emphysema group, and $14(6 \%)$ in the UNDO group. In conclusion, in our study, the types of obstructive airway diseases could be classified based on clinical, radiological, and pulmonary function test findings into five groups, including asthma, ACOS, chronic bronchitis, emphysema, and both asthma and chronic bronchitis in association with underlying emphysema (emphysema with chronic bronchitis and emphysema with asthma) or the so-called undifferentiated obstruction. We suggest that these patient groups can be determined more accurately by studies that evaluate the association between spirometric $\mathrm{FEV}_{1}, \mathrm{FEV}_{1} / \mathrm{FVC}$ values, and reversibility ratios.
\end{abstract}

Keywords: asthma, COPD, asthma-COPD overlap syndrome, reversibility, spirometry

\section{Introduction}

Asthma, chronic bronchitis, and emphysema are the most common pulmonary diseases worldwide characterized by chronic airway inflammation and airway obstruction. Airway obstruction is variable in asthma, while it is progressive and persistent in chronic bronchitis and emphysema. However, some of the patients presenting with symptoms of chronic airway diseases have clinical features of both asthma and COPD. Furthermore, both diseases have overlapping pathological and functional characteristics. Although such patients are commonly described as "asthmatic
Correspondence: Sevket Ozkaya

Cıragan Caddesi, Osmanpasa Mektebi

Sokak No 4-6, 34349 Beșiktaș,

Istanbul, Turkey

Tel +90532474 I309

Email ozkayasevket@yahoo.com
International Journal of COPD 2016:II 2009-2015

2009

Dovepress f $y$ in $\mathbf{0}$

http://dx,doi.org/10.21477COPD.S113774 (c) (7) (5) 2016 0zkaya et al. This work is published and licensed by Dove Medical Press Limited. The full terms of this license are available at https://www.dovepress.com/terms.php (c) ${ }_{\mathrm{BY}} \mathrm{NC}$ and incorporate the Creative Commons Attribution - Non Commercial (unported, v3.0) License (http://(creativecommons.org/licenses/by-nc/3.0/). By accessing the work you hereby accept the Terms. Non-commercial uses of the work are permitted without any further permission from Dove Medical Press Limited, provided the work is properly attributed. For permission for commercial use of this work, please see paragraphs 4.2 and 5 of our Terms (https://www.dovepress.com/terms.php). 
bronchitis" or "asthmatic form of COPD" in the US, the term "Asthma-COPD Overlap Syndrome" (ACOS) is recently being used to describe these patients. ${ }^{1,2}$

In this study, we aimed to classify obstructive airway diseases by clinical, radiological, and pulmonary function tests.

\section{Patients and methods}

Patients at Samsun Medical Park Hospital Chest Diseases outpatient clinic were evaluated between January 2013 and April 2016 and included in this study. The inclusion criteria were symptomatic patients (cough, dyspnea, and/or wheezing); presence of airway obstruction in spirometry (forced expiratory volume in 1 second $\left[\mathrm{FEV}_{1}\right] /$ forced vital capacity [FVC] $\leq 70 \%$ of expected); patients who had never used bronchodilators before; or patients who had not received short- or long-acting inhaled bronchodilator therapy within the recent 12 hours. The basal and postbronchodilator FVC, $\mathrm{FEV}_{1}$, and $\mathrm{FEV}_{1} / \mathrm{FVC}$ values were measured using the MIR MiniSpir PC-Based USB Spirometer by the same physician (SO) following a 30-minute resting period in an outpatient clinic setting. The test must be performed in the seated position, when the nose is clamped and nasal respiration is hindered. The patients performed the forced expiratory maneuver at least three times and the maximum $\mathrm{FEV}_{1}$ value was recorded as the basal value. Reversibility levels were evaluated as the absolute change in $\mathrm{FEV}_{1}$ and the percentage of change from the initial $\mathrm{FEV}_{1}$, calculated as $\mathrm{FEV}_{1} \% \Delta$ init: post-FEV ${ }_{1}-$ pre-FEV ${ }_{1} /$ pre $-\mathrm{FEV}_{1} \times 100$ (according to American Thoracic Society guidelines), and bronchial reversibility is defined as a drug-induced increase in $\mathrm{FEV}_{1}$ of $\geq 200 \mathrm{~mL}$ and $\geq 12 \%$ baseline. Results are presented as mean \pm standard errors of mean values.

\section{Ethical statement}

The study was performed in accordance with the ethical principles of the Good Clinical Practice guidelines and with applicable local regulatory requirements. The protocol was approved by Medical Park Hospital Institutional Review Board. All patients read the patient information form about the study procedure, and written informed consents were obtained.

\section{Results}

A total of 235 patients were included in this study. Patient characteristics are presented in Table 1. Mean age of the patients was $55.3 \pm 14.5$ (15-88) years, and male/female ratio was $190 / 45$. Mean body mass index values were 27.3 \pm 5.2 (15.1-44.3). Nonsmokers constituted $19.6 \%$ of the patients, while $34 \%$ were ex-smokers and $46.4 \%$ were current smokers. The baseline pulmonary function test results of
Table I Characteristics of patients

\begin{tabular}{|c|c|}
\hline Characteristics & Values \\
\hline Age (years), mean $\pm S D($ min-max $)$ & $55.3 \pm 14.5(15-88)$ \\
\hline Male/female & $190(80.9 \%) / 45$ (19.1\%) \\
\hline BMl; mean \pm SD (min-max) & $27.3 \pm 5.2(15.1-44.3)$ \\
\hline \multicolumn{2}{|l|}{ Smoking status } \\
\hline Nonsmoker, n (\%) & $46(19.6)$ \\
\hline Current smoker, n (\%) & $109(46.4)$ \\
\hline Ex-smoker, n (\%) & $80(34)$ \\
\hline \multicolumn{2}{|l|}{ Baseline spirometry } \\
\hline \multicolumn{2}{|l|}{$\mathrm{FVC}(\mathrm{mL})$} \\
\hline Mean \pm SD (min-max) & $2,825 \pm 1,108(710-6,870)$ \\
\hline \%Predicted \pm SD (min-max) & $74.3 \pm 22.4(24-155)$ \\
\hline \multicolumn{2}{|l|}{$\mathrm{FEV}_{1}(\mathrm{~mL})$} \\
\hline Mean \pm SD (min-max) & $\mathrm{I}, 789 \pm 774(480-4,810)$ \\
\hline$\%$ Pred \pm SD (min-max) & $58.1 \pm 20.0(20-130)$ \\
\hline \multicolumn{2}{|l|}{$\mathrm{FEV}_{1} / \mathrm{FVC}$} \\
\hline$\%$ Pred \pm SD (min-max) & $62.5 \pm 6.8(39-70)$ \\
\hline
\end{tabular}

Abbreviations: BMI, body mass index; FVC, forced vital capacity; $\mathrm{FEV}_{1}$, forced expiratory volume in I second; min, minimum; max, maximum; Pred, Predicted.

the patients were as follows: mean FVC values 2,825 $\pm 1,108$ (710-6,870) $\mathrm{mL}$ and 74.3 $\pm 22.4(24-155) \%, \mathrm{FEV}_{1}$ values

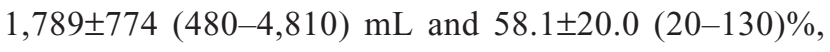
and $\mathrm{FEV}_{1} / \mathrm{FVC}$ values $62.5 \pm 6.8$ (39-70)\%. Reversibility criteria following bronchodilator treatment were present in $107(45.5 \%)$ patients. We specified five subgroups for patients according to their clinical, radiological, and pulmonary test findings, namely Group 1 (asthma), Group 2 (ACOS), Group 3 (chronic bronchitis), and Group 4 (emphysema). Additionally, a group of patients who had clinical and spirometric features of both asthma and chronic bronchitis in association with underlying emphysema (emphysema with chronic bronchitis [EWCB] and emphysema with asthma [EWA]) was defined as the undifferentiated obstruction (UNDO) group. Number and percentage distribution of patients by groups were $58(24.7 \%)$ in the asthma group, 70 (29.8\%) in the ACOS group, $61(26 \%)$ in the chronic bronchitis group, $32(13.6 \%)$ in the emphysema group, and $14(6 \%)$ in the UNDO group (Table 2). The epidemiological and

Table 2 Groups and reversibility ratios of patients

\begin{tabular}{ll}
\hline Types & $\mathbf{n}(\%)$ \\
\hline Asthma & $58(24.7)$ \\
ACOS & $70(29.8)$ \\
Chronic bronchitis & $61(26)$ \\
Emphysema & $32(13.6)$ \\
UNDO & $14(6)$ \\
EWA & $4(28.6)$ \\
EWCB & $10(71.4)$ \\
Reversibility & \\
Yes & $107(45.5)$ \\
No & $128(54.5)$ \\
\hline
\end{tabular}

Abbreviations: ACOS, Asthma-COPD Overlap Syndrome; UNDO, undifferentiated obstruction; EWA, emphysema with asthma; EWCB, emphysema with chronic bronchitis. 
Table 3 The demographic and spirometric results of groups

\begin{tabular}{|c|c|c|c|c|c|}
\hline Characteristics & Asthma & Acos & Chronic bronchitis & Emphysema & UNDO \\
\hline Age (years), mean \pm SD & $39.1 \pm 14.5$ & $57.9 \pm 10.4$ & $59.1 \pm 8.3$ & $66.2 \pm 9.6$ & $67.9 \pm 6.1$ \\
\hline Male/female & $37 / 21$ & $62 / 8$ & $47 / 14$ & $32 / 0$ & $12 / 2$ \\
\hline BMI; mean \pm SD & $27.2 \pm 5.4$ & $28.3 \pm 4.9$ & $27.5 \pm 5$ & $24.5 \pm 4.2$ & $27.5 \pm 7.3$ \\
\hline \multicolumn{6}{|l|}{ Smoking status } \\
\hline Nonsmoker, n (\%) & $26(44.8)$ & $6(8.6)$ & $12(19.7)$ & 0 & $2(14.3)$ \\
\hline Current smoker, n (\%) & $29(50)$ & $38(54.3)$ & $28(45.9)$ & II (34.4) & $3(2 \mathrm{I} .4)$ \\
\hline Ex-smoker, n (\%) & $3(5.2)$ & $26(37.1)$ & $21(34.4)$ & $21(65.6)$ & $9(64.3)$ \\
\hline \multicolumn{6}{|l|}{ Baseline spirometry } \\
\hline \multicolumn{6}{|l|}{$\mathrm{FVC}(\mathrm{mL})$} \\
\hline Mean \pm SD & $3,442 \pm I, 294$ & $2,777 \pm I, 047$ & $2,7|9 \pm 88|$ & $2,33 I \pm 783$ & $2,105 \pm 989$ \\
\hline$\%$ Pred \pm SD & $83 \pm 22.1$ & $72 \pm 21.3$ & $76.2 \pm 23.4$ & $64.8 \pm 19.2$ & $63.5 \pm 19$ \\
\hline \multicolumn{6}{|l|}{$\mathrm{FEV}_{1}(\mathrm{~mL})$} \\
\hline Mean \pm SD & $2,248 \pm 894$ & $\mathrm{I}, 724 \pm 690$ & $1,765 \pm 662$ & $\mathrm{I}, 374 \pm 588$ & $1,273 \pm 685$ \\
\hline$\%$ Pred \pm SD & $64.6 \pm 19.0$ & $55.7 \pm 18$ & $61.9 \pm 21.7$ & $48.5 \pm 18.5$ & $48.7 \pm 18.4$ \\
\hline \multicolumn{6}{|l|}{$\mathrm{FEV} / \mathrm{FVC}$} \\
\hline$\%$ Pred \pm SD & $64.7 \pm 5.7$ & $61.7 \pm 6.3$ & $64.4 \pm 6.1$ & $57.5 \pm 7.7$ & $59.6 \pm 7.1$ \\
\hline
\end{tabular}

Abbreviations: ACOS, Asthma-COPD Overlap Syndrome; UNDO, undifferentiated obstruction; BMI, body mass index; FVC, forced vital capacity; FEV , forced expiratory volume in I second; Pred, Predicted.

spirometric features of each group are presented in Table 3. The reversibility rates of the patients were $19 \% \pm 13.3 \%$ for the asthma group, $26.4 \% \pm 16.1 \%$ for the ACOS group, $8.2 \% \pm 10.1 \%$ for the chronic bronchitis group, $6.5 \% \pm 12.5 \%$ for the emphysema group, and $15.7 \% \pm 10.4 \%$ for the UNDO group. Postbronchodilator $\mathrm{FEV}_{1}$ values were as follows: asthma group $75.5 \% \pm 20.2 \%$, ACOS group $68.5 \% \pm 17.7 \%$, chronic bronchitis group $65.9 \% \pm 22.3 \%$, emphysema group $50.4 \% \pm 18.8 \%$, and UNDO group $55.5 \% \pm 19 \%$. Postbronchodilator $\mathrm{FEV}_{1} / \mathrm{FVC}$ values were as follows: asthma group $70 \% \pm 11.1 \%$, ACOS group $66.7 \% \pm 8.1 \%$, chronic bronchitis group $66.6 \% \pm 7.5 \%$, emphysema group $57.0 \% \pm 10.4 \%$, and UNDO group $58.5 \% \pm 10.2 \%$ (Table 4 ). Figures 1 and 2 present the distribution of patients according to the relationship between postbronchodilator change in $\mathrm{FEV}_{1} \%$ and basal $\mathrm{FEV}_{1} \%$ in groups and the relationship between postbronchodilator change in $\mathrm{FEV}_{1} / \mathrm{FVC} \%$ and basal $\mathrm{FEV}_{1} / \mathrm{FVC}$ in groups. We aimed for an objective classification of patients according to spirometric results in diagrams and hence created
3D MATLAB diagrams. Basal and postbronchodilator spirometric results are presented in Figures 3-5.

\section{Discussion}

Obstructive lung diseases are characterized by reduced airflow related to increased resistance caused by airway narrowing. Such obstructions cause respiratory symptoms including dyspnea, cough, sputum, and wheezing and may occur either directly by narrowing of the airway lumen or by decreased elasticity of the parenchyma surrounding the airways. $\mathrm{FEV}_{1}$ and $\mathrm{FEV}_{1} / \mathrm{FVC}$ values of the spirometric test are the best indicators for airway obstruction. ${ }^{3}$ Asthma is diagnosed based on characteristic symptoms including wheezing, dyspnea, and cough and presence of variable airway obstruction, while COPD is characterized by definitely irreversible and progressive airway obstruction. ${ }^{4}$ Spirometry is required for the diagnosis and evaluation of COPD. In COPD-suspected patients, if the ratio of $\mathrm{FEV}_{1}$ to $\mathrm{FVC}$ following bronchodilator administration is $<70 \%$, airway

Table 4 The reversibility and postbronchodilator results of groups

\begin{tabular}{|c|c|c|c|c|c|}
\hline Characteristics & Asthma & Acos & Chronic bronchitis & Emphysema & UNDO \\
\hline \multicolumn{6}{|l|}{ Reversibillity } \\
\hline Yes, n (\%) & $42(72.4)$ & $60(85.7)$ & $\mathrm{I}(\mathrm{I} .6)$ & 0 & $4(28.5)$ \\
\hline Change $(\mathrm{mL})$, mean $\pm \mathrm{SD}$ & $375 \pm 227$ & $382 \pm 168$ & $106 \pm 62$ & $5 I \pm 44$ & $172 \pm 109$ \\
\hline Change, \%pred \pm SD & $19 \pm 13.3$ & $26.4 \pm 16.1$ & $8.2 \pm 10.1$ & $6.5 \pm 12.5$ & $15.7 \pm 10.4$ \\
\hline \multicolumn{6}{|l|}{ Postbronchodilator values } \\
\hline $\mathrm{FEV}_{1}, \%$ pred $\pm \mathrm{SD}$ & $75.5 \pm 20.2$ & $68.5 \pm 17.7$ & $65.9 \pm 22.3$ & $50.4 \pm 18.8$ & $55.5 \pm 19$ \\
\hline $\mathrm{FEV}_{\mathrm{l}} / \mathrm{FVC}, \%$ pred \pm SD & $70 \pm 11.1$ & $66.7 \pm 8.1$ & $66.6 \pm 7.5$ & $57.0 \pm 10.4$ & $58.5 \pm 10.2$ \\
\hline
\end{tabular}

Abbreviations: ACOS, Asthma-COPD Overlap Syndrome; UNDO, undifferentiated obstruction; FVC, forced vital capacity; FEV , forced expiratory volume in I second; pred, predicted. 


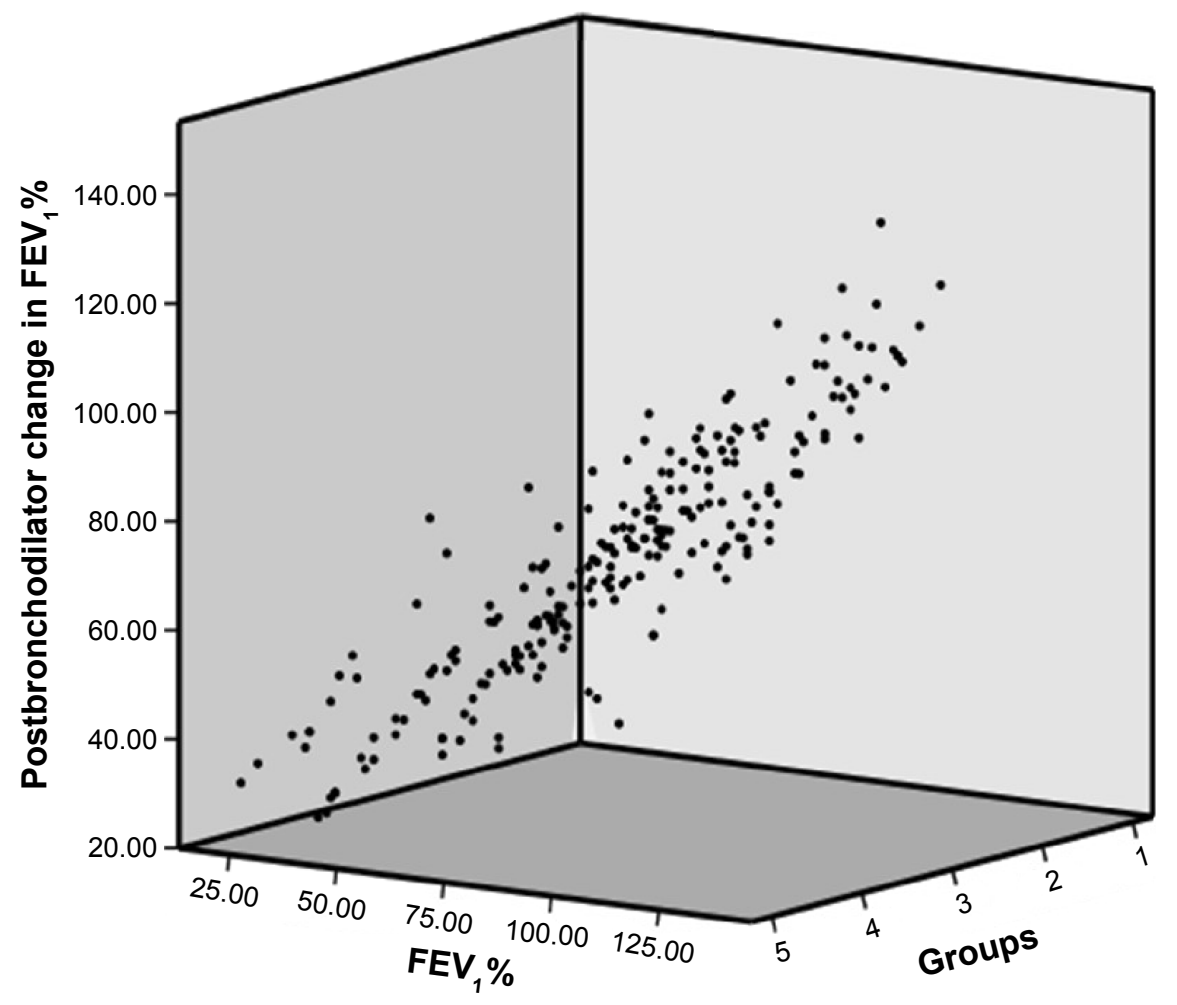

Figure I Distribution of patients.

Notes: The relationship between postbronchodilator change in FEV \% and basal FEV \% in groups: Group I (asthma), Group 2 (ACOS), Group 3 (chronic bronchitis), Group 4 (emphysema), and Group 5 (UNDO).

Abbreviations: ACOS, Asthma-COPD Overlap Syndrome; UNDO, undifferentiated obstruction; FEV , forced expiratory volume in I second.

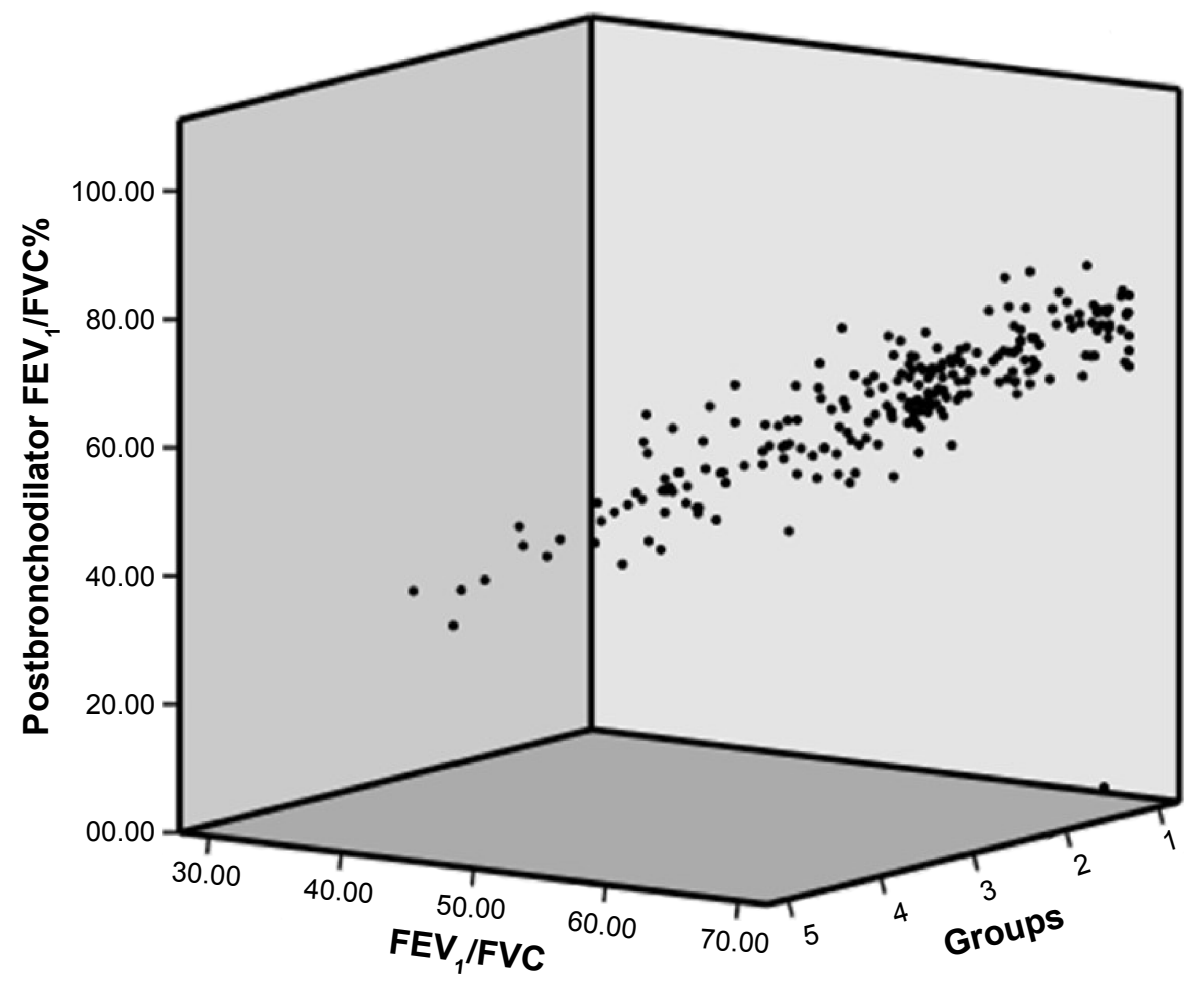

Figure 2 Distribution of patients.

Notes: The relationship between postbronchodilator change in FEV /FVC\% and basal FEV /FVC in groups: Group I (asthma), Group 2 (ACOS), Group 3 (chronic bronchitis), Group 4 (emphysema), and Group 5 (UNDO).

Abbreviations: ACOS, Asthma-COPD Overlap Syndrome; UNDO, undifferentiated obstruction; FEV ${ }_{1}$, forced expiratory volume in I second; FVC, forced vital capacity. 


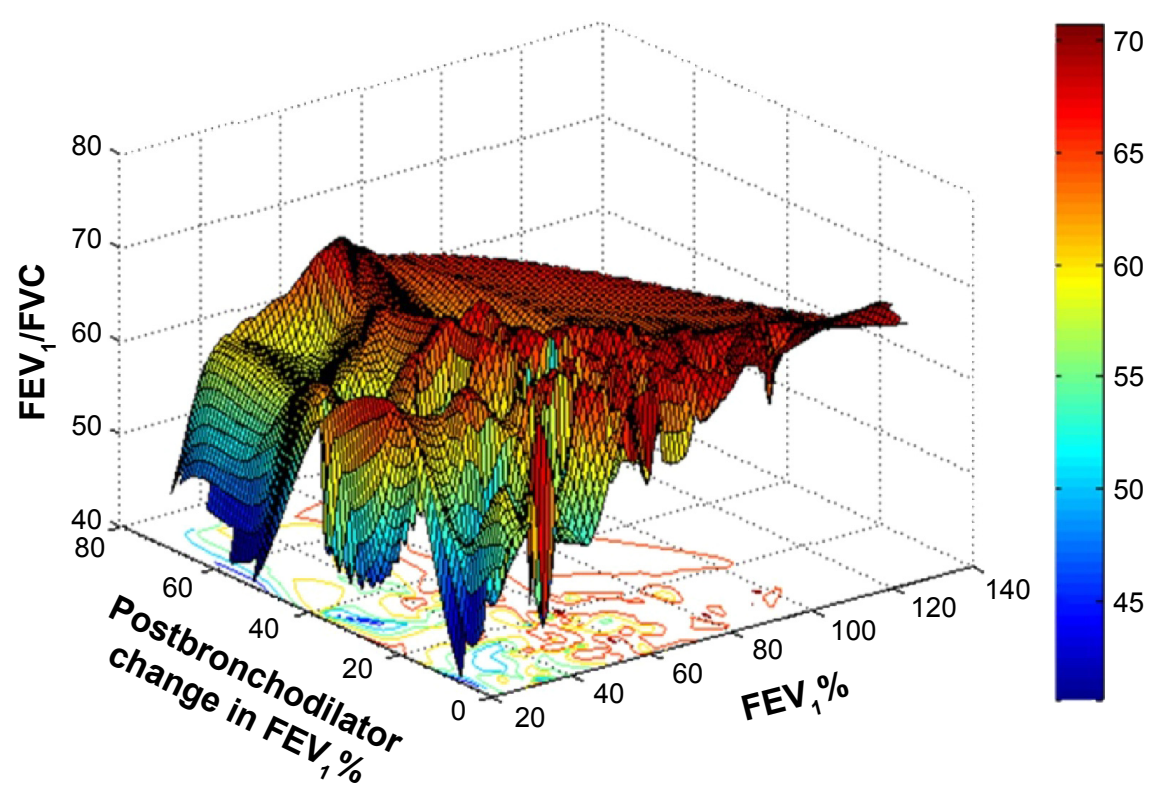

Figure 3 The MATLAB 3D figure showing the relationship between $\mathrm{FEV}_{1}$, postbronchodilator change in $\mathrm{FEV}$ \%, and basal $\mathrm{FEV}, \%$ of patients. Abbreviations: $\mathrm{FEV}_{1}$, forced expiratory volume in I second; FVC, forced vital capacity.

obstruction is confirmed and the patient is considered to have COPD. COPD is primarily classified as chronic bronchitis or emphysema. "Chronic bronchitis" phenotype, in accordance with the manifestations of chronic bronchitis, describes the patients who had expectoration and cough for 3 months or longer particularly in winter months of two consecutive years. Mucous secretions in COPD lead to excessive airway inflammation and thus cause respiratory infections, which results in further exacerbations in the chronic bronchitis phenotype. "Emphysema" phenotype patients are those who have clinical, radiological, and functional findings of emphysema and whose primary complaints are dyspnea and activity limitation. Emphysema patients generally have low body mass index, as determined in our study. This phenotype description and radiological emphysema diagnosis should be separated as various degrees of emphysema can

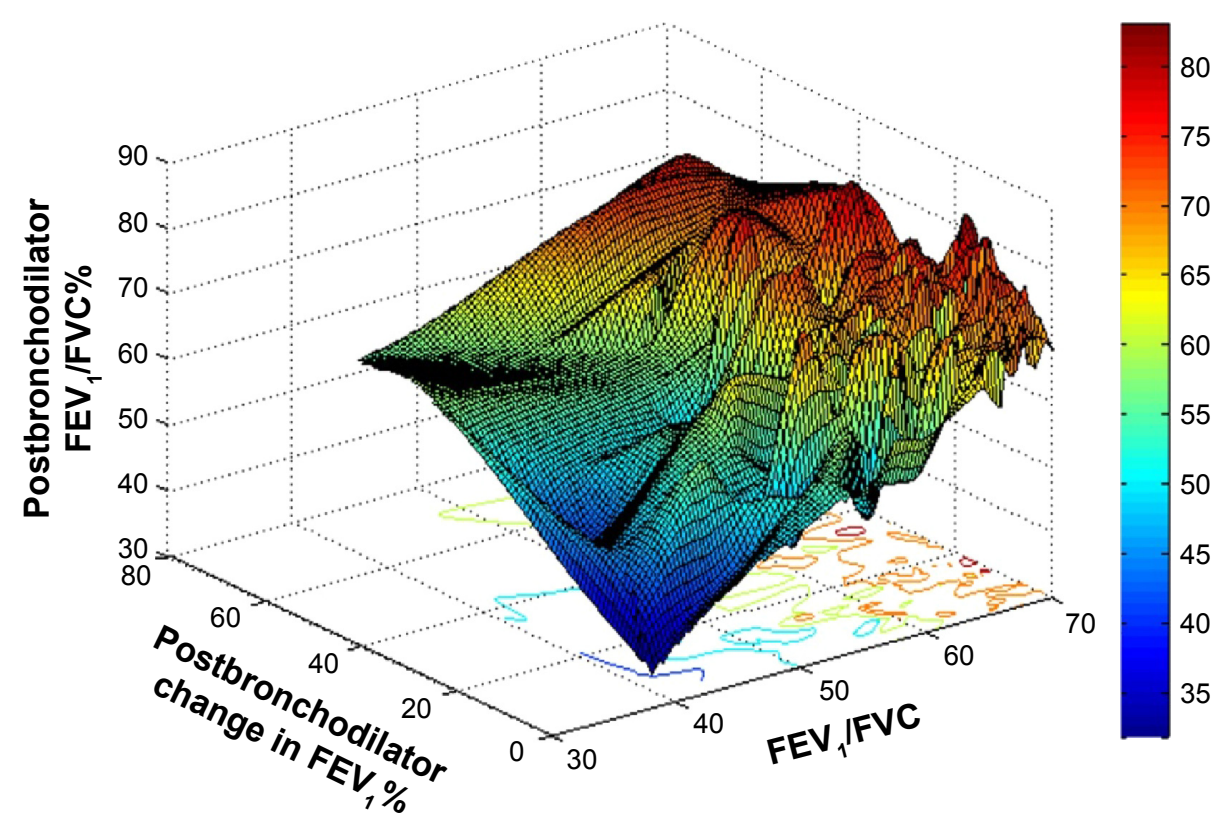

Figure 4 The MATLAB 3D figure showing the relationship between postbronchodilator $\mathrm{FEV}_{1} / \mathrm{FVC} \%$, postbronchodilator change in $\mathrm{FEV}, \%$, and basal $\mathrm{FEV}, / \mathrm{FVC} \%$ of patients.

Abbreviations: $\mathrm{FEV}_{1}$, forced expiratory volume in I second; FVC, forced vital capacity. 


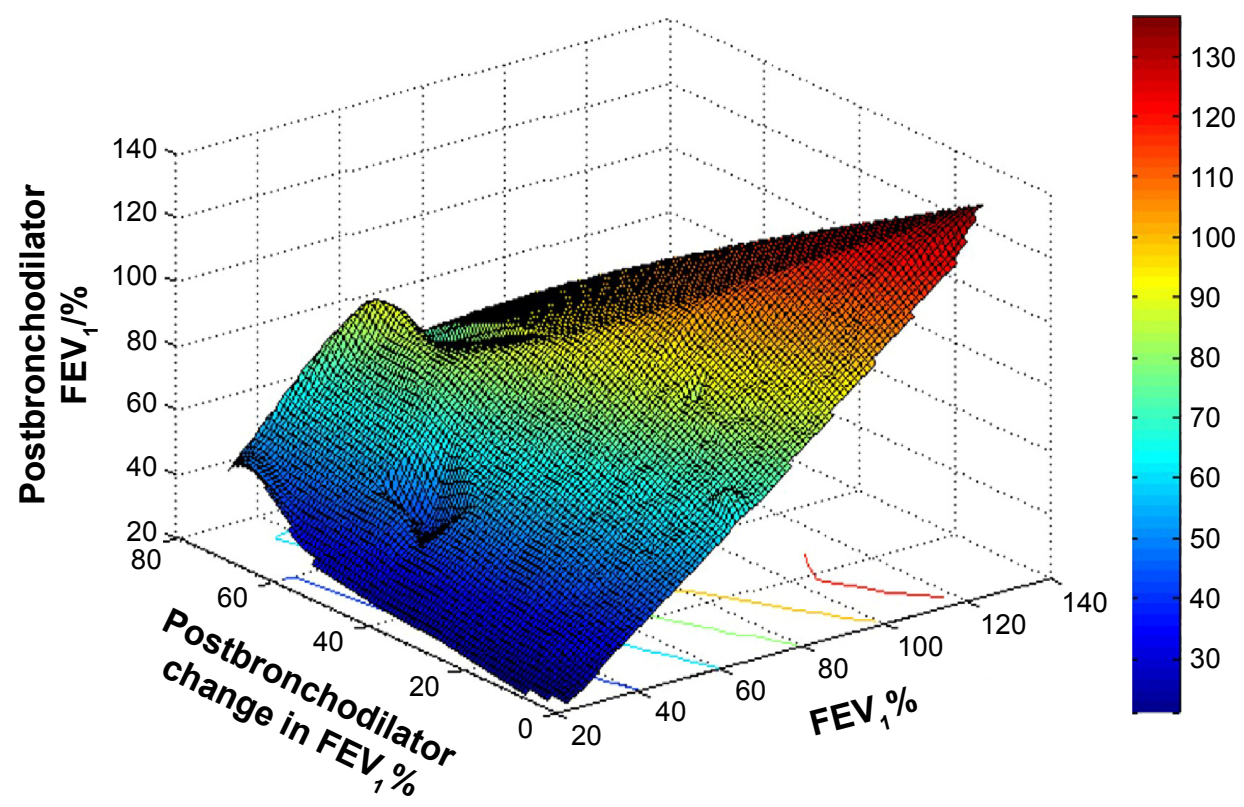

Figure 5 The MATLAB 3D figure showing the relationship between postbronchodilator $\mathrm{FEV}, \%$, postbronchodilator change in $\mathrm{FEV}, \%$, and basal $\mathrm{FEV}, \%$ of patients. Abbreviation: $\mathrm{FEV}$, forced expiratory volume in I second.

be detected on radiological examinations in patients who have airway obstruction. ${ }^{3}$ In our patient series, the patients who had clinical and spirometric features of both asthma and chronic bronchitis in association with underlying emphysema were described as the UNDO group, which constituted $6 \%$ of the patients. The patients in this group (UNDO) have severe parenchymal damage, airway obstruction, and disability.

The group with "ACOS" phenotype was characterized by definitely irreversible airway obstruction accompanied by symptoms and signs of reversibility. Various guidelines have also described significant asthma component in COPD patients or asthma-complicated COPD. The terms "Asthmatiform Bronchitis" and "Asthmatic form of COPD" were used to describe such patients in the US, and the term "Asthma-COPD Overlap Syndrome" (ACOS) is recently being used. In our study, this group included the largest number of patients who had the highest value and ratio of reversibility. Despite high reversibility values, postbronchodilator mean $\mathrm{FEV}_{1}$ value was $<80 \%$ and $\mathrm{FEV}_{1} / \mathrm{FVC}$ value was $<70 \% .^{5-8}$ In 2012 , Soler-Cataluña et al have described the "COPD-asthma overlap" phenotype with the presence of at least two of the major and minor criteria: major criteria were very high reversibility test $\left(\mathrm{FEV}_{1} \geq 15 \%\right.$; $\geq 400 \mathrm{~mL}$ ), eosinophilia in sputum, and history of asthma. Minor criteria included positive reversibility test $\left(\mathrm{FEV}_{1} \geq 12 \% ; \geq 200 \mathrm{~mL}\right.$ ), increased IgE, and history of atopy. ${ }^{9}$
The major criteria for ACOS described by Louie et a ${ }^{10}$ in 2013 included both asthma and COPD diagnosed in the patient by the same doctor, presence or history of atopy (eg, allergic rhinitis), increased IgE, age $\geq 40$ years, $>10$ pack-years smoking, postbronchodilator $\mathrm{FEV}_{1}<80 \%$ predicted, and $\mathrm{FEV}_{1} / \mathrm{FVC}<70 \%$, while the minor criteria were postbronchodilator $\geq 15 \%, \geq 12 \%$, and $>200 \mathrm{~mL}$ increase in $\mathrm{FEV}_{1}$. Results of our study were compatible with these results. The relation between $\mathrm{FEV}_{1}, \mathrm{FEV}_{1} / \mathrm{FVC}$ values, and reversibility by the patient groups is presented in Figures 1-5. The objective classifications of obstructive pulmonary diseases can be done by formulating more than two spirometric variables according to basal and postbronchodilator results.

According to Global initiative for chronic Obstructive Lung Disease (GOLD) consensus, four different phenotypes including combinations of emphysema, chronic bronchitis, frequently exacerbating, and COPD-asthma co-occurrence were described in the Spanish COPD Guidelines published in 2012: 1) chronic bronchitis or emphysema co-occurrence without frequent exacerbations, 2) COPD-asthma cooccurrence, 3) emphysema domination with frequent exacerbations, and 4) chronic bronchitis domination with frequent exacerbations. Patients who were described within as COPDasthma co-occurrence phenotype were first described under the term "Asthma-COPD Overlap Syndrome" in GOLD 2014; although this syndrome was described for patients 
with this co-occurrence, having frequent exacerbations, reduced quality of life, and faster lung function loss, the definitive criteria are not clear. ${ }^{3}$ Postbronchodilator spirometry is required for diagnosis and grading disease severity. Reversibility testing is not recommended since measuring reversibility has not contributed to differential diagnosis from asthma or determining long-term response to bronchodilator or corticosteroid treatments. However, in relation to the new definition of ACOS, we believe reversibility level could be a significant determinant and should be performed for patients with airway obstruction.

\section{Conclusion}

In our study, the types of obstructive airway diseases could be classified based on clinical, radiological, and pulmonary function test findings into five groups including asthma, ACOS, chronic bronchitis, emphysema, and both asthma and chronic bronchitis in association with underlying emphysema (EWCB and EWA) or the so-called undifferentiated obstruction (UNDO). We suggest that these patient groups can be determined more accurately by studies that evaluate the association between spirometric $\mathrm{FEV}_{1}, \mathrm{FEV}_{1} / \mathrm{FVC}$ values, and reversibility ratios.

\section{Disclosure}

The authors report no conflicts of interest in this work.

\section{References}

1. GOLD [homepage on the Internet]. Diagnosis of Diseases of Chronic Airflow Limitation: Asthma, COPD and Asthma-COPD Overlap Syndrome (ACOS) GINA. GOLD; 2016. Available from: http://www. goldcopd.org. Accessed July 23, 2016.

2. Nakawah MO, Hawkins C, Barbandi F. Asthma, chronic obstructive pulmonary disease (COPD), and the overlap syndrome. J Am Board Fam Med. 2013;26(4):470-477.

3. GOLD [homepage on the Internet]. Global Strategy for the Diagnosis, Management and Prevention of COPD, Global Initiative for Chronic Obstructive Lung Disease (GOLD). 2014. Available from: http://www. goldcopd.org/. Accessed July 23, 2016.

4. Global Initiative for Asthma [homepage on the Internet]. Global Strategy for Asthma Management and Prevention. 2014. Available from: www.ginasthma. Accessed July 23, 2016.

5. Gibson PG, Simpson JL. The overlap syndrome of asthma and COPD what are its features and how important is it? Thorax. 2009;64(8): 728-735.

6. Miravitlles M. The overlap syndrome between asthma and COPD: implications for management. Hot Top Respir Med. 2011;16:15-20.

7. Qaseem A, Wilt TJ, Weinberger SE, et al. Diagnosis and management of stable chronic obstructive pulmonary disease: a clinical practice guideline update from the American College of Physicians, American College of Chest Physicians, American Thoracic Society, and European Respiratory Society. Ann Intern Med. 2011;155(3):179-191.

8. Albert P, Agusti A, Edwards L, et al. Bronchodilator responsiveness as a phenotypic characteristic of established chronic obstructive pulmonary disease. Thorax. 2012;67(8):701-708.

9. Soler-Cataluña JJ, Cosío B, Izquierdo JL, et al. Consensus document on the overlap phenotype COPD-asthma in COPD. Arch Bronconeumol. 2012;48(9):331-337.

10. Louie S, Zeki AA, Schivo M, et al. The asthma-chronic obstructive pulmonary disease overlap syndrome: pharmacotherapeutic considerations. Expert Rev Clin Pharmacol. 2013;6(2):197-219.
International Journal of COPD

\section{Publish your work in this journal}

The International Journal of COPD is an international, peer-reviewed journal of therapeutics and pharmacology focusing on concise rapid reporting of clinical studies and reviews in COPD. Special focus is given to the pathophysiological processes underlying the disease, intervention programs, patient focused education, and self management protocols.

\section{Dovepress}

This journal is indexed on PubMed Central, MedLine and CAS. The manuscript management system is completely online and includes a very quick and fair peer-review system, which is all easy to use. Visit $\mathrm{http} / / / \mathrm{ww}$.dovepress.com/testimonials.php to read real quotes from published authors. 